\title{
Assinalando a educação ambiental a partir de uma aula problematizadora sobre o uso e descarte de pilhas e baterias
}

\author{
Highlighting enviromental education based on a problem-solving class about the usage and disposal \\ of batteries
}

Señalando la educación ambiental a partir de una clase problematizadora sobre el uso de descarte de pilas y baterías

\section{Resumo}

Este estudo descreve a aplicação e análise de uma aula problematizadora sobre a utilização e descarte inadequado de pilhas e baterias, tendo o objetivo de estimular a sensibilização ambiental em alunos do $9^{\circ}$ ano de uma escola municipal de ensino público. Nesse sentido, a intervenção didática seguiu as seguintes etapas problematizadoras: (i) primeiramente, fez-se a investigação dos conhecimentos prévios dos discentes por meio da aplicação de um questionário; (ii) em seguida, desenvolveu-se uma aula expositivo-dialogada abordando características elementares envolvidas na temática proposta; (iii) depois, propôs-se uma pesquisa extraclasse envolvendo aspectos sustentáveis da utilização de pilhas e baterias e, por fim, (iv) seguiu-se de debates sobre os resultados apontados. Como resultado, constatou-se que os conhecimentos prévios dos alunos demonstraram pouca sapiência sobre o descarte desses resíduos e base conceitual acerca do assunto. Contudo, após a abordagem dialógica-problematizadora, percebeu-se o interesse dos alunos na temática a partir de evidenciações marcadas em seu dia a dia. As pesquisas extraclasse, por sua vez, demonstraram a percepção das consequências ambientais em detrimento do descarte inadvertido desses resíduos, levando a propostas de logísticas reversa, aplicação de multas à infratores, dentre outras. Com base isso, fez-se uma comparação dos novos conhecimentos apresentados, onde percebeu-se que o descaso apriorístico, por parte dos alunos, reverteu-se em um comprometimento na adoção de atitudes sustentáveis. Assim, considera-se que esta vertente estratégica atingiu o alcance de subsidiar uma aprendizagem suficiente para desenvolver a sensibilização ambiental sobre o uso e descarte corretos desses resíduos sólidos.

Palavras-chave: Aula problematizadora; Educação ambiental; Ensino; Pilhas e baterias.

\begin{abstract}
This study describes an application and analisys of a problem-solving class about the utilization and inadequate disposal of batteries, with the objective of promoting enviromental awareness of 9th grade students of a local public school. In this perspective, a pedagogical intervention obeyed the follwing problem-solving steps: (i) initially, a survey on the students' prior knowledge was conducted through a exam; (ii) afterwards, an expository-dialoged lecture was developed adressing elementary characteristics of the subject; (iii) then an out-of-class lesson was proposed involving substainable aspects of the use of batteries and, at last, (iv) a debate about the results. As a result, it was found that the students showed little understanding of the disposal of these wastes and conceptual basis about the
\end{abstract}


subject. Nevertheless, following the dialogical-problematizing approach, it became apparent the diligence of the students in the theme based on daily noted observations. The extra-class surveys, contrastingly, demonstrated the perception of environmental consequences to the detriment of inadvertent disposal of these wastes, conveying to reverse logistics proposals, imposition of fines to offenders, and so on. Based on that, a parallel with the new presented insight, where it was noticed that the aprioristic neglect, on the part of the students, turned into a commitment in the adoption of sustainable attitudes. Thus, assesses that this strategic strand was successful subsidizing enough learning to develop environmental awareness about the correct use and disposal of this solid waste.

Keywords: Problem-solving class; Environmental education; Teaching; Batteries.

\section{Resumen}

Este estudio describe la aplicación y análisis de una clase problematizadora sobre el uso y descarte inadecuado de pilas y baterías, con el objetivo de estimular la sensibilización ambiental en alumnos de $3^{\circ}$ de la ESO de una escuela municipal de enseño público. En este sentido, la intervención didáctica ha seguido las siguientes fases problematizadoras: (i) primeramente, se hizo la investigación de los conocimientos previos de los discentes por medio de la aplicación de un cuestionario; (ii) en seguida, se desarrolla una clase expositiva y dialogada abordando características elementales envuelta de la temática propuesta; (iii) después, se propuso una pesquisa fuera de clase envolviendo aspectos sustentables del uso de pilas y baterías y, por fin, (iv) se extendió con debates sobre los resultados apuntados. Como resultado, se constató que los conocimientos previos de los alumnos demostraron poca sapiencia sobre el descarte de estos residuos y sobre la base conceptual acerca del asunto. Entretanto, posteriormente al abordaje dialógica-problematizadora, se percibió el interés de los alumnos en la temática a partir de las evidencias marcadas en su día a día. Las pesquisas fuera de clase, por su vez, demostraron la percepción de las consecuencias ambientales en detrimento del descarte inadvertido de estos residuos, llevando a propuestas de logísticas reversa, aplicación de multas a los infractores, entre otros. En base en esto, se hizo una comparación de los nuevos conocimientos presentados, donde se notó que el descaso apriorístico, por parte dos alumnos, se revirtió en un comprometimiento en la adopción de actitudes sustentables. Por lo tanto, se considera que esta vertiente estratégica logró el alcance de subsidiar un aprendizaje suficiente para desarrollar la sensibilización ambiental sobre el uso y descarte correctos de estos residuos sólidos.

Palabras clave: Clase problematizadora; Educación ambiental; Enseñanza; Pilas y baterías.

\section{Introdução}

As constantes inovações tecnológicas, como a produção e o aperfeiçoamento de equipamentos eletroeletrônicos, vêm se tornando cada vez mais intensa e requer uma demanda exaustiva de fontes de energia portátil (Rosa, Malheiros \& Bispo, 2016). Atualmente, o Brasil encontra-se entre os 10 países com a maior taxa anual de produção de lixo eletroeletrônico, ocupando a $6^{\text {a }}$ posição com um quantitativo de 1,5 milhões de toneladas, equivalendo a 7,4 $\mathrm{kg}$ por habitante (Jesus e Santos, 2021).

Sobre esse aspecto, a resolução do CONAMA n 401 de 04/11/2008 ao se reportar às pilhas e baterias, menciona que a totalidade desses detritos devem ser "encaminhadas para destinação ambientalmente adequada, de responsabilidade do fabricante ou importador”. Segundo Brum e Silveira (2011), a maioria do público consumidor pouco conhece a respeito dos perigos provenientes do descarte indevido destes materiais no meio ambiente, assim como das leis ambientais que assinalam a responsabilidade do gerador do problema em solucioná-lo.

Consequentemente, é comum nos depararmos com esses materiais sendo descartados em lixos domésticos, ruas, fontes hídricas, dentre outros locais inapropriados. Tais ações comprometem o solo, a água, a fauna e a flora da região circundante, devido ao elevado grau de periculosidade dos componentes químicos contidos nesses materiais (Arrigo, Alexandre \& Assai, 2018). Como exemplo desses componentes, citam-se os elementos Níquel, Chumbo, Mercúrio e Cádmio, que podem se infiltrar irremediavelmente na cadeia alimentar humana, desempenhando alto potencial de toxicidade ao organismo e desencadeando doenças como cânceres, lesões cerebrais, disfunções renais e pulmonares, dentre outras (Damasceno et al., 2018).

Sobre esse panorama, Bocchi, Ferracin e Biaggio (2000) fazem um apelo para que haja um gerenciamento ambientalmente adequado, a fim de atenuar a poluição e os diversos impactos sobre o meio socioambiental após a utilização 
destes materiais. Desta forma, há a necessidade de se proporcionar métodos de abordagem desta temática que visem chamar atenção para que todos possam assumir suas responsabilidades e tomar conhecimento de que suas ações são como "uma via de mão-dupla", isto é, exercendo seus direitos, mas consciente aos seus deveres.

Assim, considera-se imprescindível que essa situação-problema seja explorada no campo educacional, despertando a sensibilização ambiental a partir do envolvimento dos alunos. Pois, acredita-se que a inserção de uma problemática socioambiental, demandará do aluno um posicionamento no sentido de tomada de decisão que encaminhe à proposta(s) de solução(s). Nesse processo, é oportunizado o desenvolvimento da criticidade, pois as atividades questionadoras auxiliam os alunos a adquirir conhecimentos, formar opiniões e valores, ampliando compreensões a respeito do meio ambiente (Arrigo, Alexandre \& Assai, 2018).

Estes autores ainda destacam que elaborar práticas de Educação Ambiental (EA) por meio de ações pedagógicas conscientizadoras, viabiliza nos educandos o desenvolvimento de competências para elucidar problemas cotidianos hodiernos em nossa comunidade; cooperando com a formação de cidadãos críticos, conscientes e engajados no ambiente social em que se encontram. Em vista disso, abordagens metodológicas que interconectem os conteúdos convencionais da grade curricular às questões urgentes da humanidade - cuja origem e respostas podem ser conhecidas através da contextualização destes conceitos científicos -, são imprescindíveis.

E, uma vez que se contempla na prática escolar, recai ao docente o desafio de conduzir os alunos ao desenvolvimento de habilidades cognitivas e socioemocionais, para que estes se conscientizem e sensibilizem frente às suas funções sociais, principalmente àquelas estritamente relacionadas ao meio ambiente e seus problemas inerentes (Uhmann et al., 2017). Assim, é necessário problematizar - aliando de forma dinâmica o diálogo e conceito -, os conteúdos de maneira que abranja o contexto de vivência dos alunos para que se alcance o erigir de seu conhecimento. Neste sentido, aulas práticas que visem a reflexão e conscientização dos discentes para que desenvolvam atitudes sustentáveis e cooperem entre si, têm se configurado como uma proposta viável a ser desenvolvida (Lima \& FernadesSilva, 2018).

Essa admissão de postura é a materialização do cerne da EA, que é desenvolver no indivíduo a consciência, o conhecimento e atitudes voltadas para a preservação do meio ambiente, fornecendo informações que proporcionem novas perspectivas e posturas acerca do mesmo; para que este possa se tornar um agente ativo na sua preservação (Medeiros et al., 2011). Portanto, mais do que conceitos e informações, a EA traz possibilidades reais, que podem conduzir o aluno à autoobservação, reflexão sobre valores morais, adoção de postura crítica, reconhecimento e compreensão da responsabilidade individual que cada um tem, não apenas como um sujeito com direitos e deveres, mas enquanto ser.

Nesse sentido, este estudo foi conduzido pela seguinte questão norteadora: "Quais as contribuições pedagógicas e conceituais, voltadas à sensibilização ambiental, podem ser evidenciadas a partir de uma aula problematizadora com a temática 'o uso e descarte correto de pilhas e baterias'? Assim, este trabalho descreve a aplicação e análise de uma aula problematizadora a respeito da utilização e descarte inadequados de pilhas e baterias, tendo o objetivo de estimular a sensibilização ambiental em alunos do $9^{\circ}$ ano (Ensino Fundamental) de uma escola municipal de ensino público.

\section{Metodologia}

\subsection{Descrição do loco da pesquisa e dos sujeitos de estudo}

O desenvolvimento da proposta ocorreu numa turma do $9^{\circ}$ ano do Ensino Fundamental de uma escola municipal de ensino público do estado do Pará. A Base Nacional Comum Curricular (MEC, 2018) sugere que nos anos finais do ensino fundamental configurem-se em exploração de vivências, saberes, interesses e curiosidades dos alunos sobre o mundo natural e material que os circundam. Nesse sentido, a escolha dessa série se deu por apresentar o conteúdo integralizado de Química, Física e Biologia. Além disso, atendeu-se também à coordenação pedagógica da referida instituição, a qual já demonstrara 
interesse em subsidiar intervenções didático-pedagógicas de mesma natureza que este trabalho. Assim, através de um ofício emitido à direção escolar com a descrição dos aspectos gerais do trabalho, se formalizou a proposta.

\subsection{Definições da estratégia adotada}

Optou-se pela pesquisa qualitativa, que segundo Silveira e Córdova (2009) não se preocupa com números, mas com a compreensão da relação de indivíduos em determinado grupo social. No que tange ao ensino, esta metodologia tem sua notoriedade pelo fato de tornar o processo de ensino e aprendizagem mais interativos dentro de sala de aula, isto é, entre professor-aluno, aluno-aluno e os assuntos a serem estudados (Mól, 2017).

Sendo assim, partiu-se da premissa de que a proposição de um problema, para iniciar um conteúdo específico, fortalece a interação entre docente-aluno e o interesse pelo conteúdo. Segundo Phillips, Watkins e Hammer (2017), a noção de um problema no ensino, de forma geral, é imprescindível porque possibilita ampla reflexão a respeito de suas possíveis resoluções do ponto de vista dos alunos, conferindo ao professor o papel de auxiliar os discentes nos processos de seus afazeres; considerando que a Ciência tem seu início a partir de questionamentos referentes a determinado fenômeno ou problema.

Nesse sentido, o mecanismo metodológico adotado com os alunos, partiu-se de uma abordagem problematizadora, envolvendo aspectos históricos e os princípios físico-químicos elementares referentes ao funcionamento de pilhas e baterias, estendendo-se até os impactos socioambientais gerados pelo descarte inadequado destes materiais. Assim, desenvolveu-se esta prática durante dois dias consecutivos, sendo duas horas-aula/dia (totalizando 180 minutos). Participaram desta intervenção 18 estudantes, regularmente matriculados.

\subsection{Análise e interpretação dos dados}

Utilizou-se como método analítico dos dados a "Análise Textual Discursiva (ATD)" conforme recomendações de Moraes e Galiazzi (2006). Desta forma, o material empírico (textos produzidos pelos alunos) foi desmontado e estabelecido sobre as relações entre as unidades descritas. Com isso, estabeleceu-se 4 principais focos: desmontagem de textos; estabelecimento de relações entre as unidades descritas; captação das informações emergentes da totalidade do texto e, por fim, auto-organização dos processos de pesquisa. Isso configurou-se na unitarização, categorização e produção dos metatextos.

Visando manter o resguarde de identidade dos discentes participantes deste estudo, se designou um código específico para nomeação dos discentes no decorrer do texto, sendo utilizado termo "Estudante" seguido pelas iniciais de seus respectivos nomes.

\subsection{Intervenção pedagógica}

\subsubsection{Investigação dos conhecimentos prévios dos alunos}

A investigação do problema no loco de estudo teve por objetivo compreender a forma e a extensão em que a temática (uso e descarte de pilhas e baterias) era percebida pelos sujeitos/alunos. Isto é, descobrir o conhecimento, familiaridade e opinião crítica a respeito do uso/descarte inadequado e suas consequências socioambientais. Para tal, os sujeitos responderam a um questionário contendo 6 perguntas com o propósito de sondar a extensão de seus conhecimentos sobre o tema abordado:

1. Você sabe para que servem as pilhas e baterias e como se dá o processo do seu funcionamento?

2. Você e/ou sua família utilizam pilhas e baterias?

3. Qual o destino que você dá para as pilhas e baterias que não lhes servem mais?

4. Você conhece algum prejuízo socioambiental causado pelo descarte inadequado desses materiais? Se a 
resposta for "sim", descreva.

5. Você já presenciou alguém se desfazendo de pilhas e baterias de maneira incorreta? O que você acha disso?

6. No seu entendimento, quais medidas sustentáveis podem ser tomadas para não se descartar pilhas e baterias em locais inapropriados?

\subsubsection{Abordagem do tema "uso e descarte de pilhas e baterias"}

A partir da questão norteadora, por meio de aula expositiva e dialogada, abordou-se conceitos elementares sobre pilhas e baterias, mecanismo de funcionamento desses materiais através de uma analogia do processo de oxirredução do metal ferro, mais conhecido como "ferrugem". Posteriormente, foi demonstrado alguns dos principais impactos oriundos da contaminação proveniente do acúmulo de alguns metais pesados, principais componentes desses objetos.

Ao término, propôs-se aos alunos uma pesquisa extraclasse - a ser registrada em forma de texto e/ou ilustrações -, acerca do assunto abordado e sobre a aplicação no seu dia a dia. Os alunos pesquisariam sobre as medidas adequadas e sustentáveis para o descarte de pilhas e baterias. Ressalta-se que essa etapa foi atentamente flexibilizada à realidade particular de cada aluno, isto é, poderiam usar quaisquer fontes de pesquisa acessíveis (livros, jornais, internet etc.).

\subsubsection{Socialização da pesquisa extraclasse}

Nesta etapa, fez-se o recolhimento dos textos e/ou desenhos e iniciou-se um diálogo com os alunos mediado pelos autores deste trabalho, para que explanassem os resultados de sua pesquisa com os demais colegas; visando o compartilhamento de ideias e a interação entre os envolvidos. Essa etapa seguiu os apontamentos de Carvalho (2013), que sugere que o professor, por meio de uma série de pequenos questionamentos, deve levar o discente a transcender da ação manipulativa para a ação intelectual, para que este tome consciência como fora resolvido os problemas a partir de suas ações.

\subsubsection{Balizamento dos conceitos a partir do diálogo-ação em grupo}

Os alunos foram orientados a formarem 3 grupos, nomeados de grupo G1, G2 e G3. Para cada grupo, disponibilizouse um texto-problema referente ao consumo e descarte indevido de pilhas e baterias, bem como suas consequências; abordando também medidas preventivas e alternativas de procedências ambientalmente adequadas. Sobre os textos-problema, estes foram compilados a partir de informações extraídas de vários artigos publicados em revistas afins e adaptados para uma linguagem no limiar de compreensão cognitiva dos alunos, conforme sugere Almeida e Pagliarini (2016).

A metodologia adotada ocorreu por meio da leitura das questões e/ou textos-problema e discussão do conteúdo assimilado, buscando um consenso sobre a temática abordada em cada texto, para posteriormente as equipes externalizassem sua compreensão por meio de registro escrito ou uma exposição dialogada. Carvalho (2013) aponta que, a partir da promoção de uma atividade em que o discente é levado à reflexão afim de buscar soluções aos problemas levantados pelo mediador, fortalece-se não somente a ação manipulativa, mas a construção intelectual. E que, quando pautada na teoria Vigotskiana, vislumbra-se que as atividades em grupos propiciam maior envolvimento possível para que os membros das equipes, ao término de cada atividade, possam contribuir com uma solução para as questões levantadas.

No momento de socialização e debates dos grupos, foi utilizado um aparelho celular para gravações de áudios. Ressalta-se que esta decisão fora colocada em pauta, antes da dialética proposta, para que houvesse o acordo, tanto dos membros administrativos e coordenadoria pedagógica da instituição, quanto dos alunos envolvidos na pesquisa. 


\section{Resultados e Discussão}

\subsection{Diagnose sobre os conhecimentos prévios}

As respostas obtidas das 6 questões aplicadas, foram categorizadas conforme o Quadro 1. O valor nominal bruto dos percentuais apresentados não sumariza o grau de relevância das categorias apresentadas, apenas atestam as discriminantes das variáveis-resposta obtidas.

Quadro 1 - Categorização dos conhecimentos prévios dos alunos sobre o tema.

\begin{tabular}{|c|c|}
\hline Categorias de respostas & Percentual \\
\hline \multicolumn{2}{|l|}{ 1. Conhecimento inerente do funcionamento de pilhas e baterias } \\
\hline Desconhecimento total & $68,75 \%$ \\
\hline Atribuição à "energia interna" armazenada & $31,25 \%$ \\
\hline \multicolumn{2}{|l|}{ 2. Índice de consumo } \\
\hline Utilizam pilhas e baterias & $100 \%$ \\
\hline \multicolumn{2}{|l|}{ 3. Destinação pós-uso } \\
\hline Lixo comum & $93,75 \%$ \\
\hline Coleta seletiva & $6,25 \%$ \\
\hline \multicolumn{2}{|l|}{ 4. Consequências ambientais /saúde } \\
\hline Desconhecimento dos malefícios do descarte inadequado & $50 \%$ \\
\hline Associação da poluição ambiental a riscos para a saúde humana & $50 \%$ \\
\hline \multicolumn{2}{|l|}{ 5. Destinação por terceiros } \\
\hline Presenciaram o descarte de pilhas e baterias em locais impróprios & $50 \%$ \\
\hline Nunca presenciaram o descarte inadequado de pilhas e baterias & $50 \%$ \\
\hline \multicolumn{2}{|l|}{ 6. Medidas sustentáveis recomendadas } \\
\hline Descarte no lixo doméstico & $50 \%$ \\
\hline Acumulação/mutirão de coleta & $31,25 \%$ \\
\hline Não sabem o que fazer & $18,75 \%$ \\
\hline
\end{tabular}

Fonte: Autores (2021).

Sobre o funcionamento das pilhas e baterias, a maioria dos entrevistados $(68,75 \%)$ desconhece o princípio de funcionamento desses objetos, contudo uma parte dos sujeitos $(31,25 \%)$ expressa uma compreensão superficial, fazendo associação com algum tipo de "energia interna" presente nesses materiais. No ponto de vista cognitivo, esses resultados são concernentes quando consideramos que ainda não houve, para o nível escolar dos sujeitos, a inserção de conceitos específicos sobre fundamentos dos processos observados (reações redox, corrente elétrica etc.). Quanto à visão da funcionalidade desses materiais, podemos justapor que qualquer tentativa de expressar conhecimento sobre o fenômeno de funcionamento rendeu-se à natureza de utilidade demandada no dia a dia, que é gerar energia.

Das interrelações com o tema, em particular interesse à manipulação desses materiais, poucos alunos $(6,25 \%)$ 
relataram armazenar para coleta seletiva, alegando haver em suas residências uma seleção entre os lixos gerados. No entanto, embora que os alunos demonstrem atentar-se para esta questão, há incerteza quanto à aplicação de leis no município que efetue a destinação adequada para os insumos coletados dos residentes, não podendo-se afirmar que antes da destinação final haja processos de reciclagem ou emprego da logística reversa, tanto pela prefeitura local quanto por cooperativas privadas. Além disto, a maioria dos alunos $(93,75 \%)$ admite proceder inadequadamente nas medidas pós-uso destes materiais, descartando-os principalmente no lixo comum.

Em relação ao conhecimento de prejuízos referentes aos descartes indevidos destes materiais na natureza, houve a distribuição igualitária entre duas categorias, conforme a extensão compreensiva dos alunos. Na primeira, constatou-se desconhecimento total sobre tais consequências; e outra parte demonstra que alguns indivíduos detém um discernimento empírico a respeito dos problemas ambientais, associando-os a riscos para a saúde humana, por exemplo. Desta forma, evidencia-se dois grupos de sujeitos que se diferenciam estritamente na extensão da compreensão dos riscos atrelados à falta de precaução do descarte.

Quanto ao descarte indevido destes materiais, metade dos alunos presenciou outras pessoas descartando estes rejeitos em locais inadequados, posicionando-se contrariamente a tais práticas, demonstrando consciência dos possíveis danos que estas atitudes podem acarretar às pessoas e ao meio ambiente. Os demais alunos alegaram não perceber ou testemunhar este tipo de prática, porém não deixaram de expressar sua reprovação.

Por fim, sobre as práticas que deveriam ser tomadas para a minimização da poluição e descarte indevido destes objetos, 50\% apontam que uma solução viável à problemática ainda poderia ser o descarte destes materiais no lixo comum; $31,25 \%$ discorrem sobre o armazenamento ou mutirão de limpeza; e 18,75\% dos sujeitos admite não saber a melhor maneira de agir para solucionar tal problemática.

Desta forma, torna-se evidente a necessidade de uma intervenção com premissas de Educação Ambiental pois, sua inserção no âmbito educacional, oportuniza que o educando atue como protagonista no desenvolvimento de um planeta sustentável, não sendo apenas um espectador de sua degradação. E, também, permitirá que estes se apropriem destes conhecimentos para estar difundindo-os para o meio social onde vivem e interagem (Marques, Gonzales e Xavier, 2017), conduzindo-os a ter novas percepções e (re)construções conceituais e atitudinais que visem a resolução correta da problemática vigente deparada.

\subsection{Análise da intervenção pedagógica}

\subsubsection{Aplicação da microaula expositiva-dialogada}

Com base nos dados obtidos com o teste de sondagem, planejou-se uma microaula expositiva contemplando conceitos específicos de pilhas e baterias e alguns danos provenientes de ações indevidas de descarte do lixo gerado por estes materiais. Esta foi pautada na premissa de oportunizar uma abordagem dos conteúdos científicos relativos a pilhas e baterias e seus impactos no meio ambiente quando descartados inadequadamente. Neste caso, esse primeiro contato de conteúdos mais específicos é importante para que os alunos do ensino fundamental compreendam tais impactos e desenvolvam consciência de suas ações (Sasseron \& Carvalho, 2008).

Assim, evitando-se apresentar respostas prontas aos questionamentos dos alunos, instigou-lhes a buscar soluções com base em experiências de seu cotidiano, conforme recomenda Carvalho (2012), ao apontar que o professor não deve dispor aos alunos conceitos fechados, mas instigá-los a responder seus questionamentos com base nos seus conhecimentos espontâneos, fazendo com que estes identifiquem erros, os compreendam e reformule-os, sem que se cause constrangimentos aos estudantes durante este processo.

Nessa sistemática dialógica explanou-se conceitos sobre os princípios de funcionamento das pilhas e a diferenciação 
de baterias. Ao utilizar uma linguagem acessível percebeu-se maior interesse dos discentes quando se relacionava conceitos de reações redox com a ferrugem nas grades de ferro, por exemplo. Notoriamente, a compreensão dos alunos foi alcançada quando o conteúdo exposto se transpôs do caráter intradisciplinar para algo visível e palpável em relação a sua realidade. Considera-se que a familiaridade com os fenômenos observados no contexto diário despertou um interesse mais expressivo pelos assuntos explanados em sala.

Enfatiza-se que a articulação entre conteúdo e exemplos do dia a dia dos alunos foi importante para fazer com que os discentes interagissem mais entre si e, também, com os mediadores (docentes interinos); trazendo à tona suas curiosidades e dúvidas por meio de questionamentos levantados sobre o tema. Dessa maneira, foi possível estimular os discentes a responder suas próprias inquietações cognitivas durante diálogos questionadores oportunos aos momentos de debates.

\subsubsection{Análise dos dados da pesquisa extraclasse}

Após análise dos dados, instigou-se os alunos a fazerem uma pesquisa extraclasse com ênfase em possíveis soluções do problema apresentado a partir de uma pergunta norteadora: "Quais medidas devem ser tomadas para evitar o descarte indevido de pilhas e baterias no meio ambiente?”. Esta pesquisa foi necessária devido os dados obtidos no questionário inicial, que mesmo apresentando respostas comuns à temática abordada, assinalam uma limítrofe percepção e compreensão da gravidade da adoção de medidas não-sustentáveis a respeito do uso e descarte de pilhas e baterias, pelos discentes.

Ao analisar o texto do "Estudante AF-BE", nota-se que seu raciocínio está estreitamente relacionado com a legislação brasileira que trata das infrações e sanções administrativas ao meio ambiente. Neste caso, o aluno compreende que se deve penalizar aqueles que procedam incorretamente na destinação destes dispositivos pós-uso, descumprindo a lei ao violar as regras de proteção ao meio ambiente, conforme argumenta:

“Devem-se dar multas para pessoas que jogam pilhas, baterias e outros lixos tóxicos, no meio ambiente." (Estudante $A F-B E)$

Observa-se que o aluno se preocupa em buscar meios que atenuem os danos provenientes de condutas importunas, como o ato da contaminação ambiental. Para ele, tais atitudes devem ser desencorajadas por meio da aplicação de leis que garantam sanções, compreendendo como uma estratégia preventiva que pode dissuadir um indivíduo a praticar tais delitos. Neste sentido, Silva e Soares (2013) comentam que quando o aluno se apercebe frente a um problema de cunho históricocientífico, sendo incentivado a refletir a este respeito, a construção de seu conhecimento poderá se desenvolver a partir das conexões que ele mesmo estabelece entre aquelas informações e o seu dia a dia.

Destaca-se ainda a preocupação sobre a massiva produção de pilhas e baterias e seus principais componentes associados aos processos de contaminação e poluição ambiental, relatadas pelo Estudante JB-DS que descreve:

"Ao se desfazer de pilhas e baterias usadas em local inadequado, pode-se contaminar o solo, água e ar [...] uma única pilha pode contaminar por cerca 50 anos o solo. $O$ recolhimento e encaminhamento adequado das pilhas são responsabilidade dos fabricantes ou das empresas distribuidoras [...]" (Estudante JB-DS)

Neste caso, o aluno chama atenção para a periculosidade que estes dispositivos proporcionam às bases de sustento da vida de todos os ecossistemas terrestres (o solo, a água e o ar) quando descartados em locais inadequados, na natureza. Ainda ressalta que se trata de materiais não-biodegradáveis, compostos de substâncias tóxicas, que se expostas ao meio ambiente, manterão aquele local contaminado por décadas, desencadeando problemas que não se conterão no local de contaminação. Ele 
ainda alarma a necessidade de conscientização e providências por parte dos setores responsáveis pela fabricação e comercialização destes materiais, para que se encarreguem de não permitir o acúmulo de seu produto no meio ambiente.

O “Estudante LM-PO" trouxe em sua pesquisa os principais tópicos do conteúdo abordado, no entanto, despertou para uma problemática que estava além do proposto e questionado no decorrer da atividade, conforme mostra o trecho a seguir:

"Um cuidado que se deve ter também é com as pilhas 'piratas', de referência duvidosa, estas podem conter materiais muito mais tóxicos do que as originais, sendo muito mais perigosas" (Estudante LM-PO).

$\mathrm{O}$ aluno reflete a respeito das pilhas e baterias irregulares associando a baixa qualidade destes materiais à maiores taxas de substâncias tóxicas e/ou adição de novos elementos. Segundo Vieira et al. (2013), há incorporação de outros elementos químicos na formulação de dispositivos irregulares, destacando, em particular, o ferro. Em complementação, segundo o Instituto Nacional de Metrologia, Qualidade e Tecnologia (INMETRO) (Brasil, 2011), estes materiais apresentam não-conformidade em relação a taxa de metais pesados permitida pela resolução Conama, apresentando teor de substâncias tóxicas até 18 vezes maior que o permitido.

Tais evidências corroboram a necessidade de esclarecimento junto à população a respeito da maneira correta de adquirir e descartar estes materiais, evidenciando a necessidade de investimento no setor produtivo e na educação.

O desenho abaixo (Figura 1) ilustra a pesquisa apresentada pelo "Estudante CF-RT":

Figura 1 - Desenho elaborado como resposta do "Estudante CF-RT".

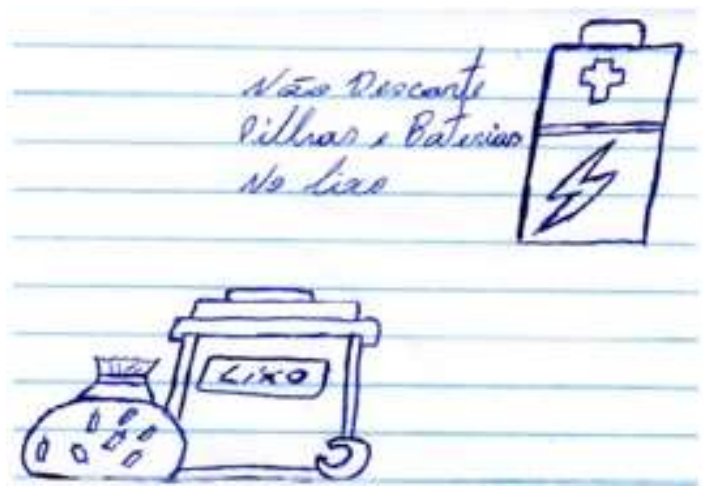

Fonte: Autores (2021).

A representação da figura demonstra que o aluno trouxe em destaque a separação do lixo doméstico dos resíduos sólidos, especificamente pilhas e baterias, com a frase "não descarte pilhas e baterias no lixo", destacando a compreensão da importância da separação seletiva para destino adequado.

Para melhor organização dos materiais recicláveis, o aluno aponta para o fato de que estes rejeitos devem passar por um processo de exclusão, na qual deve-se cumprir algumas etapas de passagens, respeitando as regras próprias da composição ou constituição de cada material, uma vez que estes não devem ser descartados em qualquer lugar.

Com isso, foi perceptível que os alunos, ao serem estimulados a buscarem possíveis soluções à problemática em questão, conseguiram compreender que pilhas e baterias são objetos que merecem atenção em seu consumo, manuseio e descarte. E que os problemas, decorrentes de ações inadequadas nestes processos, não estão distantes do contexto social ao qual estão inseridos. E ainda, admitem que é de responsabilidade de todos a adoção de medidas preventivas e sustentáveis que visem minimizar a poluição ambiental, pois é sabido que a qualidade de vida da humanidade depende da relação que estabelecemos com a natureza. 


\subsubsection{Socialização da atividade extraclasse}

Após o recolhimento dos textos, promoveu-se um breve debate no qual os alunos puderam discutir, compartilhar suas ideias e os resultados de suas pesquisas. Esta etapa foi imprescindível pois se considera que o ato argumentativo no ensino de Ciências deve ser uma prática metodológica comum no meio escolar, visto que além de favorecer a exteriorização do conhecimento adquirido, promove a capacidade de extração de conclusões de modo apropriado (Pezarini e Maciel, 2019).

Destaca-se que este momento requereu uma atenção maior dos mediadores, pois como os alunos não tinham familiaridade com debates de assuntos em sala de aula, perceptível pela resistência em participar, buscou-se diversas estratégias facilitadoras - como perguntas, brincadeiras, explanação de ideias etc. -, para que os alunos explanassem suas ideias e entendimentos sobre a temática debatida. Acredita-se que a busca por incentivo que não comprometesse as respostas dos alunos, foi crucial devido multiplicar os momentos argumentativos dos alunos de maneira espontânea, surgindo dialogação tanto com o professor quanto dos outros colegas. Do contrário, o 'medo de errar' levaria a uma participação mínima daquele momento em diante (Carvalho, 2012).

Desta forma, entre as discussões, destacou-se algumas frases colocadas em pauta pelos alunos:

“Os responsáveis pela poluição das pilhas somos nós, sendo assim, a lei da semeadura fala que o que plantarmos colheremos, igualmente é na cadeia alimentar, pois, em contato com as substâncias tóxicas, os animais se contaminarão e depois irão nos contaminar. Então nossas atitudes podem causar melhorias, porém só depende de nós mesmos." (Estudante NI-SR)

Em sua declaração, o estudante reflete de maneira crítica, mostrando-se moralmente consciente, sensibilizado e compreensivo quanto ao fato de tais problemáticas serem uma resposta ao tipo de relação que estabelecemos com a natureza e que inevitavelmente repercutirá em nossa vida. Ele reconhece a si mesmo e aos demais cidadãos como participantes ativos neste contexto, compreendendo a dimensão da repercussão de nossa interação com o meio, quer esta seja positiva quer seja negativa.

O "Estudante EL-MD", quando relaciona a lógica da lei da semeadura com a repercussão que a bioacumulação de metais pesados na cadeia alimentar tem sobre a saúde humana, ele dá ênfase a uma interrelação natural desvinculável, responsabilizando-nos como parte de um equilíbrio natural importantíssimo para a manutenção da vida conforme Roble (2009). E ainda, considera-se que esta perspectiva do aluno se evidencia em um elevado aporte de cunho científico.

"Não devemos sujar o meio ambiente porque a poluição é muito grave, traz muitas doenças que podem levar a óbito, por isso não se deve jogar pilhas e baterias na natureza. Quando jogadas nas ruas estes materiais, através da água das chuvas, vão pelas valas e esgotos parar nos rios contaminando os peixes." (Estudante EL-MD)

Observa-se ainda, que o aluno se mostra consciente e preocupado frente a gravidade desta situação e enfatiza os danos que esta poluição pode proporcionar à estrutura humana caso os componentes tóxicos destes materiais - como o cádmio, chumbo, níquel, mercúrio dentre outros - entrem em contato com o organismo. Ele percebe o descontrole ambiental que ações indevidas de poluição desencadeiam, uma vez que jogar estes materiais nas ruas é sujeitá-los ao percurso imprevisível das chuvas, valas e esgotos que transportam essas substâncias de modos irreparáveis; contaminando outros seres vivos além de nós, como os peixes.

Além disso, o aluno conscientiza que tais doenças podem ser fatais para o ser humano. A este respeito, Zendron (2015) esclarece que a intoxicação por estes metais de elevado número atômico, alteram as estruturas celulares causando lesões 
principalmente no sistema nervoso central, assim como alterações cognitivas, depressão, transtorno de déficit de atenção com hiperatividade (TDAH), dentre outros.

\subsubsection{Análise dos textos produzidos pelos grupos}

Nesta etapa, dividiu-se os discentes em 3 grupos e cada grupo recebeu 01 texto-problema. Cada texto conteve um ponto referente às problemáticas causadas pelo descarte indevido de pilhas e baterias. O texto do primeiro grupo (G1) abordou a prática de logística reversa, mostrando a lei de recolhimento destes materiais eletroeletrônicos e os meios de amenizar tal problema. O texto destacado ao grupo (G2) abordou quatro passos da reciclagem desses objetos, como a triagem, trituração, processo químico e processo com calor. O grupo (G3) discutiu sobre os diversos tipos de doenças que podem ser acometidas ao ser humano por intermédio do contato com os metais pesados presentes nas pilhas e baterias. Dos argumentos apresentados pelos grupos destacamos:

O G1, com base em seu texto, relatou que:

"[...] deve-se devolver, as pilhas e baterias, aos vendedores que a comercializam, pois, evita que estas tenham como destino quintais, lixões e ruas, porque pode prejudicar o meio ambiente, pessoas e animais. Outra alternativa seria embalar as pilhas e baterias em um plástico resistente, para não manter contato com o exterior e levá-las a pontos de coleta, evitando prejudicar os humanos e a natureza"

É de grande valia quando os alunos vislumbram tais medidas como meio de minimizar o avanço desta poluição, pois se presume que ao se deparar com situações corriqueiras desta natureza, este saberá como agir e se posicionar de maneira a tomar decisões sustentáveis. E isto se caracteriza como um ponto positivo na inserção desta prática pedagógica.

Sobre o descarte de pilhas e baterias, G2 explana que:

"As pilhas e baterias deveriam ser acumuladas e quando chegassem a uma quantidade considerável, teriam que ser enviadas para as indústrias reciclarem, além de papéis, latas, garrafas de vidro e de plástico"

Percebe-se que a colocação do G2 concilia tanto a reciclagem quando a logística reversa, visto que pilhas, baterias e materiais eletroeletrônicos possuem um destino ou tratamento recomendado por legislação e empresas especializadas nesta área de reciclagem segundo Cardoso e Cardoso (2016). Em conformidade, Jacobi (2003) assume a importância da EA no âmbito escolar e que esta colabora cada vez mais para um papel transformador, na qual a corresponsabilização dos indivíduos torna-se um objetivo essencial para a promoção de um desenvolvimento sustentável.

O G3 considerou em seu relato que:

"Podemos evitar a poluição ambiental sendo conscientes no uso destas (pilhas e baterias) pois a utilização inadequada pode acarretar doenças como paralisia, perda de coordenação motora e outras sérias consequências. Mas usando-as com devida cautela não haverá prejuizos ao meio ambiente, a nós ou as gerações futuras”

Acerca do posicionamento do G3 percebe-se a grande importância da EA para a formação dos alunos, uma vez que ela desperta nos educandos o interesse pelos problemas socioambientais presentes na sociedade. Para Silva e Terán (2018), estes valores sociais devem existir em todos os níveis de ensino, versados por todas as disciplinas escolares com base numa abordagem transversal; que contribuirá para a formação de pessoas críticas, participativas, autônomas e que desenvolvam 
atitudes frente os problemas ambientais.

\subsubsection{Apontamentos sobre a socialização dos grupos}

Após a coleta dos textos dos discentes, promoveu-se, como atividade final, uma discussão para que os grupos pudessem socializar seus aprendizados com os demais colegas. A temática do descarte indevido de pilhas e baterias foi abordada em diversos contextos ao longo do debate.

Analisando a fala dos integrantes do G1 pode-se observar uma preocupação a longo prazo quanto a essas consequências para o meio ambiente, conforme o seguinte trecho:

"Devemos ter mais consciência ao jogar lixo, tanto nos rios, como nos quintais de casa, ruas, terrenos baldios, porque tudo isso irá trazer vários prejuizos no futuro."

Dutra Júnior e Souza (2016) complementam esta ideia ao relatarem que o volume de lixo produzido atualmente está intrinsicamente relacionado a um dos principais problemas que afetam a qualidade de vida da população urbana, trazendo grandes prejuízos à saúde e meio ambiente.

Quando solicitados a socializar seu texto e suas concepções, os integrantes do G2 explanaram:

"O texto é muito interessante porque ele cita metais pesados, como o chumbo e o mercúrio que são os mais perigosos, que trazem doenças como a cegueira, epilepsia, a perda da coordenação motora, e outras. É isso que o texto vem nos alertar sobre o uso inadequado de pilhas e baterias"

Nota-se que o grupo G2 exibiu compreensão sobre as consequências oriundas da poluição de pilhas e baterias, dando enfoque em sua explicação aos malefícios para a saúde humana. Esta iniciativa reflete um ponto positivo gerado pela abordagem proposta neste trabalho, pois desafiar o aluno a lidar com problemas reais o estimula a desenvolver percepções e habilidades que o tornam protagonistas na construção de seu conhecimento e resolução de problemas conforme descreve Ferreira, Hartwig e Oliveira (2010).

Após o diálogo dos demais grupos, os participantes do G3 externaram o seguinte:

"Uma forma de solucionar esse problema [...] seria o processo de devolução de pilhas e baterias aos locais onde se comprou, pois assim se proporcionará a volta dos metais tóxicos, que tem dentro delas, aos fabricantes e assim serão reciclados e não vão parar no meio ambiente"

A predominância da logística reversa como um meio de solucionar esta problemática é eminente no argumento exposto acima. Pois, se esta fosse colocada em prática, minimizaria de forma expressiva a questão da deposição final de resíduos sólidos, eletroeletrônicas e as consequências ambientais que giram em torno destes. Daher, Silva e Fonseca (2006) explanam sobre o processo de logística reversa, em um sentido mais amplo, como todas as atividades, logísticas de coletar, desmontar e processar produtos e/ou materiais e peças; usados com intuito de garantir uma recuperação sustentável.

Por fim, se perguntou se os textos e as demais atividades implicariam em uma tomada de atitudes diferentes das adotadas até aquele momento, obtendo-se as seguintes respostas:

G1: "Nunca prestamos muita atenção nesse assunto de descartar esses materiais em locais apropriados, mas com 
todas essas informações que vocês trouxeram nós teremos mais cuidado quando for jogar fora esses materiais.”

G2: "Tentaremos fazer as coisas certas, como descartar devidamente esses lixos e não simplesmente se livrar em qualquer lugar."

G3: "Vamos tentar pôr em prática a logística reversa devolvendo aos comércios, mas será difícil porque a maioria que eu conheço não recolhem pilhas e nem baterias."

Com base nessas declarações, pôde-se notar que os alunos passaram a compreender sobre a extensão das consequências geradas, tanto ambientais quanto em relação ao próprio ser humano. Além disso, a partir deste momento, segundo os próprios discentes, houve comprometimento de mudanças em seus hábitos a fim de minimizar tal situação, adotando medidas e atitudes sustentáveis. Deste modo, infere-se que houve uma expressiva contribuição da estratégia metodológica adotada para a (re)significação e (re)estruturação de moral crítica dos sujeitos participantes.

\section{Considerações Finais}

A partir da temática proposta, propiciou-se ao aluno a auto-observação, a reflexão sobre seus valores morais, a criticidade, a liberdade de ação, o reconhecimento e compreensão da responsabilidade individual que cada um detém; não apenas como cidadão em cargos diferentes (aluno e professor, por exemplo) com direitos e deveres, mas enquanto ser. Logo, a aplicação de aulas baseadas em problematização de questões ambientais mostrou-se uma estratégia meritória na suscitação da sensibilização ambiental que, consequentemente, propiciou aos alunos a consciência moral a partir do conhecimento da repercussão que o processo inadequado de seleção, utilização e descarte de pilhas e baterias pode gerar no meio ambiente.

Embora a maioria dos alunos, a princípio, tenha admitido não se atentar para tais questões, a partir do diálogo e observação proporcionados pelo método aplicado, estes puderam estabelecer relações entre a temática discutida e o que acontece corriqueiramente em sua realidade. E, desta forma, puderam posicionar-se crítica e ativamente frente à tais questões; percebendo o surgimento de preocupação em solucioná-las à medida que a consideração de mudanças conceituais, atitudinais e comportamentais começaram a ser feitas, a fim de minimizar os problemas socioambientais provenientes do desconhecimento e da administração inadequada destes dispositivos.

Considera-se, portanto, que houve êxito dos objetivos pré-estabelecidos à medida que se observou a ocorrência de ressignificação conceitual, procedimental e atitudinal por parte dos alunos após a intervenção metodológica; que contribuiu para a arquitetura de conhecimentos despojados e adoção de medidas sustentáveis, legitimando a importância da Educação Ambiental no contínuo do processo educacional.

Assim, encorajamos que propostas pedagógicas que visem estabelecer conexões diretas dos conhecimentos abordados em sala de aula com as problemáticas hodiernas vivenciadas pelos discentes, sejam tomadas de forma contínua e nos diferentes níveis de ensino; pois permitem a incorporação dos conceitos de maneira eficaz ao despertar o senso autocrítico dos sujeitos. E sobre esse aspecto, estes tornam-se capazes de apontar os erros e soluções sobre uma perspectiva daquilo que os circunda, isto é, sobre sua postura e a interrelação com o ambiente. Desta forma, sugerimos que trabalhos futuros, pautados nessa vertente, possam atingir ambientes extraescolar, estabelecendo um viés de ação dinâmica com os demais sujeitos sociais que também assumem papéis fundamentais em todo esse processo.

\section{Referências}

Almeida, M. J. P. M., \& Pagliarini, C. R. (2016). Leitura na Educação em Ciências. Ciênc. educ. (Bauru), 22(2), $271-277$.

Arrigo, V., Alexandre, M. C. L., \& Assai, N. D. S. (2018). O Ensino de Química e a Educação Ambiental: Uma proposta para trabalhar conteúdos de pilhas e 
baterias. Experiências em ensino de ciências, 13(5), 306-325.

Brasil. INMETRO. (2011). Relatório sobre análise em pilhas alcalinas e zinco - manganês._https://www4.inmetro.gov.br/

Bocchi, N., Ferracin, L. C., \& Biaggio, S. R. (2000). Pilhas e Baterias: Funcionamento e impacto ambiental. Química nova na escola, 11(3), 03-09.

Brum, Z. R., \& Silveira, D. D. (2011). Educação ambiental no uso e descarte de pilhas e baterias. Revista em gestão, educação e tecnologia ambiental, 2(2), 205-213.

Cardoso, F. C. I., \& Cardoso, J. C. (2016). O problema do lixo e algumas perspectivas para redução de impactos. Cienc. Culto., 68(4), 25-29.

Carvalho, A. M. P. (2012). Os estágios nos cursos de licenciatura. Cengage Learning.

Carvalho, A. M. P. (2013). O ensino de ciências e a proposição de sequências de ensino investigativas. In Carvalho, A. M. P. (org.). Ensino de ciências por investigação: condições para implementação em sala de aula (pp. 1-20). Cengage Learning.

CONAMA - Conselho Nacional de Meio Ambiente - $\mathrm{n}^{\mathrm{o}}$ 401, de 04 de novembro de 2008. (2008). Estabelece os limites máximos de chumbo, cádmio e mercúrio para pilhas e baterias comercializadas no território nacional e os critérios e padrões para o eu gerenciamento ambientalmente adequado, e dá outras providências. Ministério do Meio Ambiente. Brasília, DF: Diário Oficial da União, seção 1. https://www.jusbrasil.com.br/diarios/DOU/2008/11/05/Secao-1?p=10

Daher, C. E., Silva, P. S., \& Fonseca, A. P. (2006). Logística reversa: oportunidade para redução de custos através do gerenciamento da cadeia integrada de valor. BBR-Brazilian Business Review, 3(1)

Damasceno, C. H. Carbo, L., Moretti, R. L., Joerke, G. A. O. (2018). Abordagem sobre o descarte inadequado de lâmpadas fluorescentes, pilhas e baterias no ensino de ciências. Revista Prática Docente, 3(2), 492-505.

Dutra Júnior, A. N. P. S., \& Souza, R. V. (2016). Diagnóstico e espacialização do risco ambiental aplicado ao manejo do lixo doméstico em Ituiutaba-MG. Geoambiente On-line, (26).

Ferreira, L. H., Hartwig, D. R., \& Oliveira, R. C. (2010). Ensino experimental de química: uma abordagem investigativa contextualizada. Química Nova na Escola, 32(2), 101-106.

Jacobi, P. (2003). Educação Ambiental, Cidadania e Sustentabilidade. Cadernos de Pesquisa, (118), 189-205.

Lima, R. B., \& FernandesSilva, C. M. L. (2018). O descarte das pilhas e baterias como tema de ensino em grupos cooperativos. Experiências em Ensino de Ciências, 13(1), 198-210.

Marques, R., Gonzalez, C. E. F., \& Xavier, C. R. (2017). As Dificuldades da Inserção e da Prática em Educação Ambiental no Currículo Escolar. In XVI Encontro Paranaense de Educação Ambiental. Curitiba: Setor De Educação Da UFPR. http://www.epea2017.ufpr.br/wp-content/uploads/2017/05/140-E4-S13AS-DIFICULDADES-DA-INSER\%C3\%87\%C3\%830-1.pdf

Medeiros, A. B. Mendonça, M. J. S. L., Sousa, G. L., \& Oliveira, I. P. (2011). A Importância da educação ambiental na escola nas séries iniciais. Revista Faculdade Montes Belos, 4(1), 1-17.

Mól, G. S. (2007). Pesquisa qualitativa em ensino de química. Revista Pesquisa Qualitativa, 5(9), 495-513.

Moraes, R., \& Galiazzi, M. C. (2006). Análise textual discursiva: processo reconstrutivo de múltiplas faces. Ciência \& Educação (Bauru), 12(1), 117-128.

Pezarini, A. R., \& Maciel, M. D. (2019). Avaliação dos argumentos e das argumentações produzidas pelos estudantes de ciências e biologia a partir de uma proposta didática pautada em Toulmin e Bonini. Revista de Ensino de Ciências e Matemática, 10(1), 27-47.

Phillips, A. M., Watkins, J., \& Hammer, D. (2017). Problematizing as a scientific endeavor. PHYS. REV. PHYS. EDUC. RES., 13(2), 1-13.

Roble, O. (2009). Conhecimento do Homem, da Natureza e da Sociedade. Curitiba, PR: IESDE.

Rosa, S. C. S., Malheiros, J. B., \& Bispo, A. G. P. (2016). Descarte Adequado De Pilhas E Baterias Usadas: Uma Abordagem Para A Educação Escolar Indígena. Educon, 10(01), 1-11.

Sasseron, L. H., Carvalho, A. M. P. (2008). Almejando a Alfabetização Científica no ensino fundamental: A proposição de e a procura de indicadores do processo. Investigação em ensino de ciências, 13(3), 333-352.

Silva, B. O., Câmara, S. C., Afonso, J. C., Neumann, R., \& Alcover Neto, A. (2011). Série histórica da composição química de pilhas alcalinas e zincocarbono fabricadas entre 1991 e 2009. Química Nova, 34(5), 812-818.

Silva, F. S., \& Terán, A. F. (2018). Práticas Pedagógicas na Educação Ambiental com estudantes do ensino fundamental. Experiências em Ensino de Ciências, $13(5), 339-351$

Silva, V. A., \& Soares, M. H. F. B. (2013). Conhecimento Prévio, Caráter Histórico e Conceitos Científicos: O Ensino de Química a Partir de Uma Abordagem Colaborativa da Aprendizagem. Química nova na escola, 35(3), 209-219.

Silveira, D. T., \& Córdova, F. P. (2009). A pesquisa científica. In Gerhardt, T. E., Silveira, D. T. (org.). Métodos de Pesquisa (pp.44-58). Editora da UFRGS.

Uhmann, R. I. M., Radetzke, F. S., Kunst, R., Malinowsk, M. M., \& Boht, M. (2017). Contextualização Da Educação Ambiental No Ensino De Ciências e Química. In $37^{\circ}$ Encontro Nacional de Debates sobre Ensino de Química., FURGS. https://edeq.furg.br/images/arquivos/trabalhoscompletos/s04/ficha-14.pdf.

Vieira, L. H. C., Silva, R. G., Silva, B. O., Henrique Júnior, S. S., Câmara, S. C., \& Afonso, J. C. (2013). Avaliação da qualidade de pilhas alcalinas e zinco- 
Research, Society and Development, v. 10, n. 9, e53510918126, 2021

(CC BY 4.0) | ISSN 2525-3409 | DOI: http://dx.doi.org/10.33448/rsd-v10i9.18126

carbono de diferentes procedências. Eclética Química, 38, 9-24.

Zendron, R. (2015). Mecanismos de neurotoxicidade e doenças neurológicas relacionadas à intoxicação por metais pesados. Revista Brasileira de Nutrição Funcional, 15(64), 45-51. 